\title{
Emotional Geographies of the Uncanny \\ Reinterpreting Italian Transnational Spaces
}

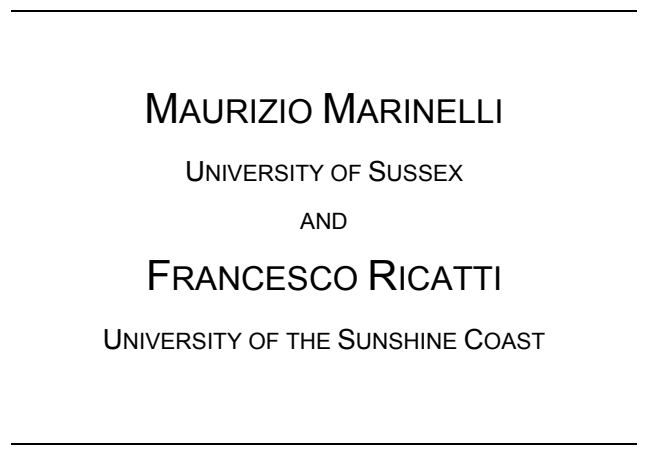

Your home is your heart: it is where you feel secure, you share your pleasures and your treasures with your family.

Mirka Mora, 'Home Sweet Home'1

This special section of Cultural Studies Review aims to read transnational spaces constructed and inhabited by Italian migrants and settlers to Australasia as emotional spaces of uncanny perceptions, memories, narratives and identities. As poignantly expressed by Ziarek, 'affect is crucial in the formation of national affiliation because it mediates between the emptiness of time and language, and the imaginary organic unity of the nation.'. ${ }^{2}$ If essentialist identities seem to dominate the political discourse about the Nation, it is also apparent that beyond this rhetoric, nations are 'marked by cultural difference and the heterogeneous histories of 
contending peoples, antagonistic authorities, and tense cultural locations' ${ }^{3}$ From this perspective, the migrants' difference is not threatening because it challenges the unity of the nation, but rather because it mirrors the alterity, the otherness that already exists within the nation. It is here that the concept of the uncanny becomes particularly pertinent, expressing one's emotional reaction when s/he is in front of something or someone that is stranger and other and yet at the same time familiar, precisely because of his or her otherness.

We argue that, for the same reason, emotions are central to the understanding of diasporic and colonial lives, identities and memories, and that in fact the uncanny emotional space between the reification of an imaginary unity and the acceptance of the void, which is at the core of our subjectivity, is a central aspect of transnational lives. As argued by Royle, the uncanny is 'to be associated with an experience of the threshold, liminality, margins, borders' ${ }^{4}$ This collection aims to test this association in specific, although ever shifting, changing and displacing, contexts of social interaction and cultural production. We chose the opening quote by famous Australian visual artist Mirka Mora, who was born in France from a Lithuanian father and a Romanian Jewish mother and migrated to Australia after surviving the Holocaust. The artwork of this transnational subject poignantly embodies the emotional geographies of the uncanny experience of home as revealed by the artist's multiple layers of subjectivity. Mora depicted Aboriginal activist Charles Perkins, together with three Anglo-Celtic faces, and with the opening sentence challenges our understanding of 'home' represented by the so-called Federation style family house, which allegedly conveys the idea of stability, while alluding to a possible illusion of stability since one can see emptiness behind the beauty of the facade. The doubleedge sword of 'home' is a subtle thread that connects the essays in this issue and substantiates their investigation of emotional complexities.

Pioneering work on emotional geographies has recognised that emotions are crucial to negotiating difference and identity in the human experience of space. ${ }^{5}$ On a different but highly complementary level, Ann Stoler's groundbreaking research on intimacy and colonial practices in the Dutch Indies signalled a broad rethinking of colonial categories. ${ }^{6}$ Stoler's 'tracking the intimate' interface of colonial relationships and practices in the Dutch colonial Indies relates to comparative concerns that this collection extends to the genealogies of the political and the intimate in the 
transnational experiences of Italians in Australasia. In this sense, the collection of essays offers, for the first time, a coherent focus on the socio-spatial dimension of the Italian experiences in Australia, China (specifically Tianjin) and Japan. These experiences are investigated through a unified analytical perspective that goes beyond the simple study of the relationship between the imagined communities of the coloniser vis-à-vis the colonised.

The theoretical framework for this collection is an aesthetic one. When referring to aesthetics we have in mind the definition proposed by Freud, for whom aesthetics is 'not merely the theory of beauty, but the theory of the qualities of feeling'. ${ }^{7}$ Our argument is that such a frame is vital for those scholars who aim to develop a history of emotions that is not simply a history of how emotions have been told, imposed and denied by intellectuals, artists, clerics, doctors and politicians, but is also a history of emotional lives and memories; a history in which emotions play an important, if always ambiguous and complex, role in individual and collective lives and memories. In recent years we have seen the publication of important works on Italian migrants' emotions, sentiments and intimacy, ${ }^{8}$ but the aesthetic qualities of migrants' feelings have rarely been investigated from a critical and theoretical point of view. Our contention is that these qualities also have political relevance, in so far as they emphasise how migrants' bodies are positioned into social and cultural spaces where migrants produce, project, reject and negotiate different and often contradictory experiences of inclusion and exclusion. Within such an aesthetic framework, we have then decided to test in specific geographical and historical contexts the centrality of the uncanny. This is one of the most influential and controversial aesthetic concepts developed in the last hundred years, and one that has found particular resonance in theoretical and literary studies about migration and postcolonialism, but it has rarely been applied to in-depth research about specific geographical and historical contexts of migration, settlement and transnationalism.

Drawing inspiration from the Freudian suggestions about the uncanny (das unheimliche), and later interpretations by philosophers such as Heiddeger, Derrida, Kristeva, Bhabha, Žižek and Ahmed, we refer to the uncanny as the emotional reaction to something that is, at the same time, familiar and unfamiliar, homely and unhomely. The uncanny then becomes an aesthetic frame through which 
experiences of migration and colonialism can be read and interpreted. How have Italians experienced the strange un/familiarity of the places to which they have migrated or that they have colonised in Australasia? And, in the process of familiarising the unfamiliar, how have they perceived the strange familiarity of the newly emerged 'Italian' spaces that they have first constructed and then inhabited, outside the boundaries of the Italian Nation, and often within the space of other essentialist nations? Furthermore, how have they related to the places they have left in Italy: the places to which they have progressively become strangers yet have continued to constitute a central element of their subjectivity?

It is in attempting to answer such complex questions that the concept of the uncanny becomes particularly useful. In his 1919 essay, Freud suggests that the meaning of uncanny does not correspond to unfamiliar. ${ }^{9}$ He recalls Schelling's definition of the uncanny as something which ought to have been kept concealed but which has nevertheless come to light. He explains that the German adjective heimlich means belonging to home, familiar, intimate, but can also have the meaning of something that is kept at home, and is therefore withheld from others, secretive, disquieting; here is where the meaning of heimlich comes to coincide with its supposed antonym unheimlich, meaning uneasy, eerie, bloodcurdling. ${ }^{10}$ The theoretical fruitfulness of the concept of the uncanny therefore relies on its potential for investigating emotions arising from migration from, to and within historical, geographical and social spaces that are not simply hybrid and liminal, but also, and simultaneously, familiar and unfamiliar. In addressing this complex issue, we consider theorists who have given different, but we believe often complementary, answers to a more general question: what does produce uncanny feelings?

The foundations of the most significant answers to this question come from Freud and Heidegger, and at times from a combination of the two. Freud interpreted the uncanny as resulting from the return of the repressed, something of our past that we have repressed but which suddenly comes back and is therefore strangely familiar. Heidegger instead relates uncanniness to Dasein, as a constitutive, rather than acquired, element of the human condition: it is about being in the world and yet never really being at home in it; it is about our insistent attempt to be and feel at home as a response to our radical and primordial condition of unhomeliness. ${ }^{11}$ Heidegger's interpretation is a reminder for scholars of migration that one might 
already not feel at home before the process of migration, and migration might in fact be in many instances a response to a sense of loss and bewilderment, rather than its cause. $^{12}$

In more recent years, the popularity of the concept has produced new debates and interpretations. ${ }^{13}$ While it is not possible here to delve into what has been a long and complex development in aesthetic and psychoanalytical thinking, for our purposes we should at least refer to Derrida and Žižek. Derrida has developed the notion of haunting; that is, something from the past interrupting unpredictably the present, often in the shape of spectral fantasies. ${ }^{14}$ If on the one hand Derrida seems to recall the Freudian return of the repressed (past), on the other hand he seems to share Heidegger's understanding of uncanniness as a constitutive and incessant element of Dasein: 'there is no Dasein without the uncanniness, without the strange familiarity (Unheim Dasein lichkeit) of some spectre'. ${ }^{15}$ This interpretation was particularly successful in generating what has been called the 'spectral turn' in literary studies as well as urban studies, with the uncanny often coming to correspond with spectral and ghostly manifestations. ${ }^{16}$ A related and important explanation of the uncanny is offered by Žižek, who, following Lacan, argues:

the most familiar things take on a dimension of the uncanny when one finds them in another place, a place that 'is not right'. And the thrill effect results precisely from the familiar, domestic character of what one finds in this Thing's forbidden place. ${ }^{17}$

This interpretation opens up a very important question for scholars of migration: what does happen when the familiar is not found 'at home' but rather abroad; that is, when is not only the familiarity of home to be challenged, but also the unfamiliarity of the places to which one migrate?

The theory of the uncanny has also been deployed by scholars to better understand the complex position and positioning of 'the other', especially within (post)colonial societies. Kristeva first employed the concept explicitly in relation to migration. ${ }^{18}$ For Kristeva we are strangers to ourselves, and therefore the other mirrors our own otherness, so that in the unfamiliarity of the other we perceive our own (familiar) otherness. She further argues that in order to reduce the anxiety and fear we experience in front of the uncanny, we should therefore deal first of all with the other within ourselves. A second important development of this theory in 
relation to migration and postcoloniality has been suggested by Bhabha, through his reinterpretation of the uncanny as the unhomely, which is in fact the most accurate translation of the German das unheimliche theorised by Freud. ${ }^{19}$ In Bhabha's analysis, the explicit reference to home in the word unhomely well expresses the centrality of the articulation between the private and the public spheres in the hegemonic identification of the colonised other, so that, for instance, 'the recesses of the domestic space become sites for history's most intricate invasions' ${ }^{20} \mathrm{~A}$ third, essential interpretation is argued by Ahmed, for whom the uncanny results from specific categories of knowledge which tell us in advance how 'the other' is supposed to be, so that we are already familiar with what is to be identified as strange and unfamiliar. ${ }^{21}$

All the theories briefly sketched above, stemming from or relating to Freud's original suggestions, are not in contradiction with each other, but rather might offer a complementary and more nuanced understanding of the many complex historical, social and cultural layers that determine and influence migrants' experience of the uncanny. However, if one intends to apply these broad, philosophical theories to the study of migration and colonial settlement, it is essential that a proper historicising is set in place, to avoid the risk of existentialist, and often almost transcendental, conclusions. This risk is particularly apparent in Derrida's and Kristeva's works about the uncanny. While Derrida's theory seems particularly relevant when using the uncanny to interpret historical events and their relevance and influence in the present, it has also been noted that 'the generalised structure of haunting is symptomatically blind to its generative loci'. ${ }^{22}$ Luckhurst argues that this 'very generalised economy of haunting' can be challenged by interpreting spectralisation as 'a grounded manifestation of communities in highly delimited locales subjected to cruel and unusual forms of political disempowerment'. ${ }^{23}$ While he is here referring to Gothic literature, we share with him the conviction that it is most import to locate spectral phantasies and other manifestations of the uncanny within specific geographical, historical and political contexts.

Despite Kristeva's intention to emphasise the political nature and relevance of the uncanny in her work Strangers to Ourselves, and although she mostly refers to the French context, her inability or unwillingness to remain close to her specific historical context produces two major shortcomings. First, she seems to blend the 
cosmopolitan intellectual, such as herself, with other foreigners such as workingclass migrants and refugees, thus failing to consider major and essential relations of power, including race and class. Second, she does not propose an effective political response to the power of the uncanny in relation to migration. Kristeva suggests instead a vague, psychoanalytical and at times existential need to recognise and accept the foreigner within ourselves. Ahmed, on the contrary, seems to be well aware of the need to refer to specific historical and geographical contexts. She is particularly concerned with the risk of conflating all migrants into the generic category of 'the other', a category whose lack of specificity ends up essentialising migrants and thus reinstating hegemonic categories. This section of Cultural Studies Review therefore originates from the awareness that the concept of the uncanny proves useful for scholars interested in a theoretically complex and rich understanding of migrants' emotions, nationalism, (post)colonialism and xenophobia only in so far as it goes beyond a generic understanding of the cultural production of the other.

Another point to be made is that the concept of the uncanny in relation to migration has been prevalently applied to explain the hostile attitudes of the hosting societies towards migrants. This collection inverts the focus, by concentrating on migrants' own uncanny feelings, and their experiences of the uncanny, the unhomely and the unfamiliar in relation to migration and colonialism. This is particularly important when considering that proper and fruitful negotiations between various, complex and contradictory migrants' groups and local communities require a better understanding of the feelings and emotions experienced by all sides of the negotiation.

If Italian transnational spaces have been constructed around a certain imagery of Italy and Italianness, but also of Italian local spaces and identities and as aspirations to an imagined community, these transnational spaces also depend on a specific perception of, and negotiation with, the space 'other': the space in which such emotionally charged identities are reinvented, reproduced and ultimately experienced in loco. As argued by Hobsbawn first and Bhabha later, nations should be understood from the perspective of those who inhabit their margins, as they are able to reveal the imaginary nature of the nation's unity. ${ }^{24}$ However, one must also consider that migrants themselves carry with them imaginary ideas of unity. The question this issue poses is, therefore, if and how the uncanny manifests itself not 
only in response to migration, but also and above all in the acts of migration, and in the processes of settlement and colonisation of space.

The broad and varied scope of this issue, ranging from Italian experiences of migration and settlement in Australia to contemporary interpretations of Italianità (usually translated in English as Italianness) in Australia, Japan and China, is an attempt to test in different geographical and historical contexts the fruitfulness of an aesthetic approach based on the concept of the uncanny. The articles insightfully respond to our original provocation to engage with the emotional geographies of the uncanny, both in theoretical and empirical terms.

Giorgia Alù, in her article 'Uncanny Exposures: Mobility, Repetition and Desire in Front of a Camera', engages with Freud's definition of the uncanny exploring, in particular, its ocular-centrism, the exploration of ways of seeing and concealing, or not seeing, and ultimately the impact of the new, the different and the repressed on personal imagination and emotions. Alù uses the uncanny to shed light on new aspects of the Italian migration in relation to photographic images. Her insights derive from the premise that visual arts have often been the subject of analysis for the sense of alienation, anxiety and disquiet they are able to cause in the viewer. Photography, in particular, through emotions and desire is both an uncanny and fascinating means of representation, through its blurring of fiction and reality, human and machine, familiar and unfamiliar, past and present. Alù demonstrates how migration and photography are fundamental aspects of modernity and transnational lives leading both to conditions of otherness and disembodiment. Both migration and photography are, in fact, seen as liminal spaces in between life and death, presence and absence, Self and Other.

Paolo Bartoloni, in 'The Interstitial Language and Transnational Experience' addresses the notion of the interstitial and the transnational through a discussion of writings by some of the most important European thinkers of the twentieth century (Heidegger, Benjamin, Freud and Lacan) on language, individual identity and collective belonging. Bartoloni offers a compelling analysis of the workings of the uncanny with a particular focus on the Italian Forum in Leichhardt, Sydney. The 
uncanny provides a means of exploring the notion of identity in this space, which constitutes a unique mirror of broader, transnational and interrelated identities; the Italian Forum can be used to search for a lost origin in the past, and to recognise the typical trait of duality and hybridity in the present. Bartoloni argues that, in this case study, Freud's theory of the uncanny is particularly appropriate to open up issues of translation, adaptation, and reification in which difference and unfamiliarity emerge. He poignantly concludes that the foreign echoes resonating in language are nothing more than our own face under a different light or slightly distorted, precisely as it happens in a mirror.

Maurizio Marinelli's essay, 'The Triumph of the Uncanny: Italians and Italian Architecture in Tianjin', explores the emotional geographies of the uncanny in the microcosm of the former Italian concession in Tianjin (recently rebaptised 'New ITown'). The essay engages with the complexity of the possible translations of the concept of 'uncanny' in Chinese, through the historicisation of the 'uncanny' in relation to the representations of Italy in China. Marinelli proposes a nuanced understanding of the 'uncanny', analysing the domestication of the foreign space. The Chinese space was perceived as foreign, and ultimately 'uncanny', by the Italian colonial power when the concession was acquired in 1901. The uncanny Chinese space was progressively tamed and ultimately transformed in another uncanny locale, a sort of 'Italian neighborhood' dominated by Italian-style architecture. However, in the last two decades, the foreign, and uncanny, Italian design and architecture have been reappropriated to assert both Tianjin's and China's growing international influence via 'soft power', and thus contribute to the construction of a-bilaterally useful-ultra-positive image of China's relations with other countries, Italy included. The double-edged sword of the 'uncanny' offers a new methodological perspective to explore the identity politics both of Italy in China, and of urban China itself.

Toshio Miyake, in 'Italian Transnational Spaces in Japan: Doing Racialised, Gendered and Sexualised Occidentalism', engages with the concept of the uncanny with particular attention to the relationship between Italy and Japan. The article's framework is configured within the wider hegemony of modern Occidentalism, inspired by Antonio Gramsci's pioneering remarks on the notions of 'the West' and 'the East'. ${ }^{25}$ To investigate how Italian transnational spaces in modern and 
contemporary Japan are invested with complex projections of un/familiarity, Miyake focuses on the interrelational, intersectional and positional articulation between Occidentalism, Orientalism and self-Orientalism. The interrelational approach highlights how imagined and emotional geographies of 'Italy' in Japan have been shaped by the asymetrical and liminal positions of both nation-states in regards to the centre of colonial and imperialist capitalism. This study argues that it is the founding ambivalence of modern Japan and Italy as both orientalising and orientalised nation-states that has to be repressed to guarantee the reproduction of Occidentalism; however, this periodically resurfaces, haunting the reassuring alleged unity of 'the West', 'the East', 'Italy' and 'Japan'. The intersectional approach points to the intertwined and cumulative effect of multiple dimensions of identification and othering in the intra-societal level (civilisation, nation, class, race/ethnicity, gender, sexual orientation, and so on). This enables Occidentalism to cross-cut different levels of discourses, representations and emotions, ultimately resulting in it having a naturalising effect as an almost invisible and 'inferential' hegemony. ${ }^{26}$ The positional approach provides a more space- and time-specific perspective. This allows Miyake to focus on the consumer-driven Italian boom in Japan during the 1990s, which elevated Italy to the most loved foreign country among the whole female and young population. More specifically, Miyake's innovative approach offers the opportunity to investigate the dis/conjunctive impact and self-reflexive potential of the Othering gaze on the subjective experience of Italian young migrants in Japan in terms of whiteness, gender and sexual orientation.

Francesco Ricatti's essay, 'The Emotion of Truth and the Racial Uncanny: Aborigines and Sicilians in Australia', aims to disrupt prevailing narratives about Italian migration to Australia through a decolonising historiographical approach and an imaginative historical analysis of four personal anecdotes. These anecdotes, which illustrate the complexity and importance of encounters between Sicilians and Aborigines in Australia, are here considered as historical sources that effectively challenge prevailing and hegemonic historical interpretations. The concept of the racial uncanny, with its focus on the un/homely nature of the migrant encounter with the indigenous 'other', comes to play three central functions in the analysis of the anecdotes. First, it relates the too often naturalised 'fear of the other' to 
entrenched cultural paradigms operating within specific historical contexts. Second, it shows how the cultural politics of racialised emotions in a migratory and colonial context can result in contrasting and contradictory cultural, social and political experiences. Finally, it produces new and multilayered historical narratives that recognise and value the power of emotional dialogues and encounters in shaping our individual and collective, private and public, relationship with the past. It is from this perspective, Ricatti argues, that truth, and especially historical truth, should be conceptualised as an emotion.

Ilaria Vanni's essay, 'Oggetti Spaesati, Unhomely Belongings: Objects, Migrations and Cultural Apocalypses', is grounded in an analysis of first person narratives on objects of Italian migrants arrived in New South Wales in the postwar years. Vanni's case study is Belongings: Post-WW2 Migration Memories \& Journeys, an ongoing online exhibition curated through the NSW Migration Heritage Centre (MHC) at the Powerhouse Museum, and supported by the Community Relations Commission for a Multicultural NSW. Vanni demonstrates her primary interest in introducing a parallel reflection on the uncanny through the writing of Italian philosopher and anthropologist Ernesto De Martino, whose work has yet to receive its due attention in the English speaking scholarship. In the early 1960s, De Martino worked on the idea of 'the end of the world', and his notes were collected and published posthumously in 1977 by Clara Gallini and Marcello Massenzio in the book La Fine del Mondo. ${ }^{27}$ De Martino also published an article on apocalypses (intended as the end, perceived or real, of a lifeworld) in 1964. In writing about apocalypses, De Martino deploys the idea of spaesamento: the loss of one's country, village, home, bearings in the world (but also displacement, misplacement, confusion, sense of unhomeliness, uncanny), which as a word has been used as an Italian translation of 'the uncanny'. ${ }^{28}$ The idea of cultural apocalypses is particularly relevant to thinking about emotional geographies in relation to migration. In this sense, Vanni's article contributes to the theorisation of the uncanny from a different cultural history and sensibility, in conversation with the other essays in this special issue.

As all the essays demonstrate, the use of the uncanny as an interpretive paradigm allows the intimate interconnection between the familiar and the unfamiliar to be illuminated, as well as offering a more nuanced appreciation of the 
interplay between the geographical, the cultural and the psychological 'tyranny of distance'. If this project has produced a new sort of historical analysis, in which the constructed Italian lives and reproduced Italian-style spaces are seen for their contingent, untidy mixture, then it will have been true to the editors' and authors' primary concern. They hope to have collapsed the apparent dichotomy between 'external' and 'internal' spaces, since these spaces are mutually constructive and ultimately convergent in the ways they reflect and impact upon emotions.

\footnotetext{
-NOTES

${ }^{1}$ Mirka Mora's vignette with this quote appears on the top corner of the sixth panel in the Federation Tapestry Suite, Melbourne Museum. The ten-panel tapestry was commissioned to Murray Walker, with the assistance of Mirka Mora and Bruce Petty, to mark the Australian Centenary of Federation in 2001. In the sixth panel, Mora portrays Aboriginal leader Charles Perkins (1936-2000) engaging in an imaginary dialogue with three Anglo-Celtic Australians.

${ }^{2}$ Ewa Ziarek, 'The Uncanny Style of Kristeva's Critique of Nationalism', Postmodern Culture, vol. 5, no. 2, 1995, par.14.

${ }^{3}$ Homi Bhabha, 'DissemiNation: Narrative and the Margins of the Modern Nation', in Homi Bhabha (ed), Nation and Narration, Routledge, London and New York, 1990, pp. 291-322, p. 299.

${ }^{4}$ Nicholas Royle, The Uncanny, Manchester University Press, Manchester, 2003, p. vii.

5 See Joyce Davidson and Liz Bondi, 'Emotional Geographies of Gender and Sexuality, Spatialising Affect, Affecting Space', Gender, Place and Culture, vol. 11, no. 3, 2004, pp. 373-4; Joyce Davidson and Christine Milligan, 'Embodying Emotion, Sensing Space: Introducing Emotional Geographies', Social and Cultural Geography, vol. 5, no. 4, 2004, pp. 523-32; Joyce Davidson, Liz Bondi and Mick Smith (eds), Emotional Geographies, Ashgate Press, Aldershot, Hampshire, 2005.

${ }^{6}$ Ann Stoler, Carnal Knowledge and Imperial Power: Race and the Intimate in Colonial Rule, University of California Press, Berkeley, 2002.

${ }^{7}$ Sigmund Freud, 'The "Uncanny"', in Sigmund Freud, Standard Edition, vol. 17 (1917-1919), pp. 219 252, originally published in German as Sigmund Freud, 'Das Unheimliche', Imago, vol. 5, nos 5-6, pp. 297-334.

${ }^{8}$ See Loretta Baldassar, 'Missing Kin and Longing to Be Together: Emotions and the Construction of Copresence in Transnational Relationships', Journal of Intercultural Studies, vol. 29, no. 3, 2008, pp. 24766; Loretta Baldassar and Donna R. Gabaccia (eds), Intimacy and Italian Migration: Gender and Domestic Lives in a Mobile World, Fordham University Press, New York, 2011; Sonia Cancian, Families,
} 
Lovers and their Letters: Italian Postwar Migration to Canada, University of Manitoba Press, Winnipeg, 2010; Francesco Ricatti, Embodying Migrants: Italians in Postwar Australia, Peter Lang, Bern, 2011.

${ }^{9}$ Freud.

${ }^{10}$ Freud, p. 226.

${ }^{11}$ See Martin Heidegger, Being and Time, trans. Joan Stambaugh, State University of New York Press, Albany NY, 1996, pp. 176-7.

${ }^{12}$ An interesting application of Heidegger's understanding of the uncanny to the study of existential decisions to migrate can be found in Greg Madison, 'Existential Migration', Existential Analysis, vol. 17, no. 2, pp. 238-60.

${ }^{13}$ See Anneleen Masschelein, The Unconcept: the Freudian Uncanny in Late-Twentieth-Century Theory, State University of New York Press, Albany NY, 2011.

${ }^{14}$ Jacques Derrida, Spectres of Marx: The State of the Debt, the Work of Mourning, and the New International, Routledge, New York, 1994, originally published in French as Spectres de Marx, Editions Galileé, 1993.

${ }^{15}$ Derrida, p. 100.

${ }^{16}$ See Roger Luckhurst, 'The Contemporary London Gothic and the Limits of the "Spectral Turn”', Textual Practice, vol. 16, no. 3, 2002, pp. 527-46; and John Wylie, "The Spectral Geographies of WG Sebald', Cultural Geographies, vol. 14, no. 2, 2007, pp. 171-88. Both articles represent good examples of this trend, while also referring to numerous other studies within the same framework. A particularly interesting example of the fruitfulness of the concept of spectrality in urban studies, especially in regard to migration, can be found in Jo Frances Maden, 'Spectres of Migration and the Ghosts of Ellis Island', Cultural Geographies, vol. 15, no. 3, 2008, pp. 359-81.

${ }^{17}$ Slavoj Žižek, Looking Awry: An Introduction to Jacques Lacan through Popular Culture, The MIT Press, Cambridge and London, 1991, p. 145.

${ }^{18}$ Julia Kristeva, Strangers to Ourselves, Columbia University Press, New York, 1991, originally published as Étrangers à nous-mêmes, Paris, Fayard, 1988.

${ }^{19}$ Homi Bhabha, 'The World and the Home', Social Text, no. 31-32, 1992, pp. 141-53.

${ }^{20}$ Homi Bhabha, The Location of Culture, London, Routledge, 1994, p. 9.

${ }^{21}$ Sara Ahmed, Strange Encounters: Embodied Others in Post-Coloniality, Routledge, London and New York, 2000, pp. 21 and 184 (note).

${ }^{22}$ Luckhurst, p. 528. For a more general critique of Derrida's inability to relate to any specific sociohistorical account, and the de facto transcendental character of his constant attempt of undermining any transcendental thinking, see Nigel Mapp, 'Spectre and Impurity: History and the Transcendental in Derrida and Adorno in Ghosts: Deconstruction, Psychoanalysis, History, ed. Peter Buse and Andrew Stott, London, Macmillan Press, 1999, pp. 92-124.

${ }^{23}$ Luckhurst, p. 536.

${ }^{24}$ Bhabha, 'DissemiNation', p. 291. 
25 Antonio Gramsci, Quaderni del carcere, ed. Valentino Gerratana, Einaudi, Turin, 1975, pp. 1419-20.

English translation from Antonio Gramsci, Gramsci: Prison Notebooks, trans. Joseph A. Buttigieg, Volume III, Columbia University Press, New York, 2010, p.176.

26 Stuart Hall, 'The Whites in Their Eyes: Racist Ideology and the Media', in The Media Reader, eds Manual Alvarado and John O. Thompson, British Film Institute, London, 1990, pp. 7-23.

27 Ernesto De Martino. La Fine del Mondo. Contributo all'Analisi delle Apocalissi Culturali, Einaudi, Torino, 2002 (1977).

28 Graziella Berto, Freud, Heidegger: Lo spaesamento, Bompiani, Milano, 2002 (1999). 